Original Research

\title{
Mandatory continuing education for pharmacists in a developing country: assessment of a three-year cycle
}

\author{
Hala SACRE (D), Samah TAWIL (D), Souheil HALLIT ID, Georges SILI, Pascale SALAMEH ID). \\ Received (first version): 5-May-2019 Accepted: 18-Aug-2019 Published online: 24-Aug-2019
}

\begin{abstract}
Background: In Lebanon, mandatory continuing education (CE) for pharmacists was implemented in January 2014.

Objective: The objectives of this study are to assess 1) the overall adherence to the mandatory CE program, 2) pharmacists' preferences related to $\mathrm{CE}$, and 3 ) barriers to adherence to $\mathrm{CE}$.

Methods: By the end of October 2017, an evaluation of pharmacists' participation in the mandatory CE program was conducted using electronic reports available in the Learning Management System (LMS). Descriptive results were presented as frequencies and percentages. In addition, a cross-sectional survey was conducted among pharmacists to better understand their preferences and barriers to their participation to the CE program. Finally, a focus group was organized with pharmacists who did not start their CE.

Results: Out of all registered pharmacists in Lebanon, $68.30 \%$ started their CE and $25.6 \%$ already achieved their required credits. Among pharmacists enrolled in the CE system, the majority (69\%) used the online courses at least once. Moreover, CE enrolment was similar among old and young pharmacists except for those newly registered. The majority of pharmacists preferred clinical and pharmacological topics, followed by preventive medicine and transferable skills. Barriers to engaging in CE were mainly work and family obligations, lack of interest, lack of time, and difficulties in commuting and technology use.

Conclusion: Although results of the present study are similar to those in developing countries, the resistance to change is higher. The Lebanese Pharmacists Association [Ordre des Pharmaciens du Liban] should develop strategies to motivate and enroll more pharmacists in the CE system, based on the barriers and preferences cited in the results, while continuing to offer high quality and cost-favorable CE programs to Lebanese pharmacists.
\end{abstract}

Keywords

Education, Pharmacy, Continuing; Pharmacists; Professional Practice; Motivation; Attitude of Health Personnel; Developing Countries; Focus Groups; Surveys and Questionnaires; Lebanon

\section{INTRODUCTION}

Continuing Education (CE) is an internationally recommended approach that allows pharmacists to acquire the knowledge, skills and ethical attitudes necessary to stay current and competent in their practice, as insufficient knowledge, limited skills, and inappropriate attitudes may be obstacles to achieving satisfactory health outcomes. ${ }^{1-3}$ The educational strategies and competency-based approaches that are successfully used for pre-graduate training must be maintained and expanded throughout the practitioner's career, beyond the entry-to-practice level; this would define the characteristics of the pharmacy profession. $^{1,4-7}$

A growing body of evidence demonstrates that not all health care workers actively participate in CE activities once they begin to practice, even in developed countries. In

Hala SACRE. Drug Information Center. Lebanese Pharmacists Association; \& Clinic for Epidemiology and Toxicology, National Institute of Public Health (INSPECT-LB). Beirut (Lebanon). halasacre@hotmail.com

Samah TAWIL. Drug Information Center and Continuing Education

Department. Lebanese Pharmacists Association. Beirut (Lebanon). samah.tawil@opl.org.lb

Souheil HALLIT. Clinic for Epidemiology and Toxicology, Nationa Institute of Public Health (INSPECT-LB); \& Faculty of Medicine \&

Medical Sciences, Holy Spirit University of Kaslik (USEK). Jounieh (Lebanon).souheilhallit@hotmail.com

Georges SILI. Continuing Education Department. Lebanese Pharmacists Association. Beirut (Lebanon). gmsili@hotmail.com Pascale SALAMEH. Clinic for Epidemiology and Toxicology, National Institute of Public Health (INSPECT-LB); \& Faculty of Pharmacy and Faculty of Medical Sciences, Lebanese University. Hadath (Lebanon). pascalesalameh1@hotmail.com
Japan, where CE is not mandatory, the major challenge is to involve pharmacists in CE cycles. ${ }^{2,8,9}$ In low- and middleincome countries, some aspects of CE may not be adequately addressed, and accreditation or quality assurance systems may be lacking or have to be improved. ${ }^{3,10}$

Regarding the Middle East and North Africa region, CE was implemented in some countries such as the United Arab Emirates and Qatar, whereas it is still lacking in others. The current role of the Emirates Pharmacy Society is limited to providing certified $\mathrm{CE}$ credit hours required by the Emirates Ministry of Health to renew most of the medical practitioners' licenses on a yearly basis, while its initial role was to promote the pharmacy practice and the advancement of pharmaceutical sciences. ${ }^{11}$ In Qatar, the established CE model reflects a wide spectrum of international approaches to life-long learning. In fact, almost half of pharmacists are in favor of the mandatory CE system for annual licensure. ${ }^{12}$ On the other hand, in Yemen, pharmacists are not required to pursue additional training after graduation, nor is CE openly encouraged. ${ }^{13}$ As for Egypt, no recertification for pharmacy licensure is mandated for registered pharmacists and community pharmacists are not interested in $\mathrm{CE}$, owing to low salary incomes and the absence of motivating career pathway. ${ }^{14}$

In Lebanon, to be able to practice, pharmacists should register with the official pharmacists' association, the Lebanese Pharmacists Association [Ordre des Pharmaciens du Liban] (OPL). The OPL was established by law in 1950 and represented the commencement of a new era in 
pharmacy practice. Its main goal is to advance pharmacy practice and support pharmacists. Within OPL structure, an appointed Scientific Committee has the role of organizing educational activities including conferences, congresses and publishing newsletters. CE activities were started in the late nineties through conferences and selected articles published in an internal newsletter. As the CE was not mandatory, organized activities were not on a regular basis except for the annual 3-day congress and the annual pharmacists' day.

In November 18, 2011, the law 190 on the "Mandatory Continuing Education to Pharmacists" was enacted in the parliament (Table 1). According to this law, each pharmacist registered with the OPL has to complete 15 credits per year, of which at least 5 should be live (the remaining 10 may be done either live or through online courses), and all courses and activities organized by the OPL should be offered to pharmacists free of charge. It is noteworthy that the law does not distinguish between $\mathrm{CE}$ and Continuing Professional Development (CPD), pharmacists are therefore allowed to choose topics freely. $^{15}$

To better serve the established CE system, a Learning Management System (LMS) that includes online courses of interest to the majority of pharmacy sub-specialties (including clinical, community and hospital topics, clinical laboratory, psychology, etc.) was adopted to manage the pharmacists' CE credits. ${ }^{16}$ This system is available free of charge to all participants. To help pharmacists enroll in the system, the OPL offered live training sessions across Lebanese regions throughout 2014. The purpose of these sessions was to explain to pharmacists how to create their accounts and how to take online courses and tests available through the LMS platform. Furthermore, an explanatory manual was developed, printed and distributed to pharmacists who attended these sessions and a PDF version was made available online.

Because it was expected to be unpopular among pharmacists, law 190 was only enforced in January 2014, 3 years after its adoption, without any previous situation assessment to evaluate the readiness and willingness of pharmacists to join a CE program; therefore, it is hypothesized that a large number of pharmacists would show a resistance to change and/or have other issues that may be potential barriers (lack of time, lack of interest, logistic difficulties, etc.) as in other developing countries. ${ }^{10,17}$ The extent to which pharmacists enrolled in OPL CE program and the potential barriers preventing them from doing so, have never been evaluated yet in Lebanon.

Therefore, the objectives of this study are to assess 1 ) the overall adherence to mandatory CE program, 2) pharmacists' preferences related to $\mathrm{CE}$, and 3) barriers to adherence to $\mathrm{CE}$.

\section{METHODS}

The current manuscript is divided into: the LMS data, the registered pharmacists' survey (quantitative on a sample), and the focus group on encountered barriers (qualitative on a sample).

\section{Learning Management System data}

The number of registered pharmacists and their date of registration were collected from the OPL database. At the end of October 2017, the number of registered pharmacists enrolled in the CE program was assessed through electronic reports generated using the LMS. These reports included credits earned by attending live activities, and those earned by taking online courses and tests through the LMS. Live activities are created and recorded manually in the LMS, which allows generating comprehensive reports on participants' activities.

\section{Registered pharmacists' survey}

A cross-sectional observational study was conducted between February and May 2017, using a random sample of 628 Lebanese pharmacists from all districts of Lebanon. All pharmacists were eligible to participate; the sample consisted of those who agreed to complete the questionnaire that was developed and reviewed by ten experienced academics and pharmacy practitioners and comprised four distinct sections. Section 1 clarified sociodemographic characteristics, including years of experience in pharmacy practice, the number of working hours per day, and the highest degree achieved. Section 2 was designed to obtain information about technology and computer literacy; questions included the ease of access to the LMS platform to take online courses. Section 3 was designed to assess the pharmacists' communication with OPL. Section 4 included questions about value and motivation regarding $\mathrm{CE}$, and reasons for rarely/not adhering to OPL CE program. The questionnaire was then piloted on a sample of 10 pharmacists prior to its finalization and distribution. The pilot study revealed no need for modification; its results were thus included in the study. Further methodological details are available in another publication. ${ }^{18}$ Statistical analyses were performed using SPSS version 23 (IBM SPSS Software, Chicago, IL, USA). Descriptive statistics were calculated using counts and percentages for categorical variables.

\section{Focus group on encountered barriers}

A focus group was organized by the authors to assess the reasons why several pharmacists are not adhering to $C E$.

Table 1. Overview of the Law 190 on the "Mandatory Continuing Education to Pharmacists"

This law applies to all registered pharmacists living on the Lebanese territory whether working or not. Pharmacists living abroad are exempted from the system after presenting the appropriate proofs.

The cycle is of 3 years during which pharmacists have to achieve a total of 45 credits of which 15 at least should be live. The counter is turned to zero after each cycle.

Pharmacists are allowed to achieve all their credits as live credits but they are not allowed to achieve them all online.

Pharmacists who fail to achieve their credits in due time, will be suspended until achieving the required credits.

Registered pharmacists should be provided with the necessary tools and opportunities to achieve their credits at no cost (online and live).

The CE Committee of the OPL has the role of supervising, managing and accrediting scientific and educational activities. It is nominated by the advisory board and has a yearly mandate. 


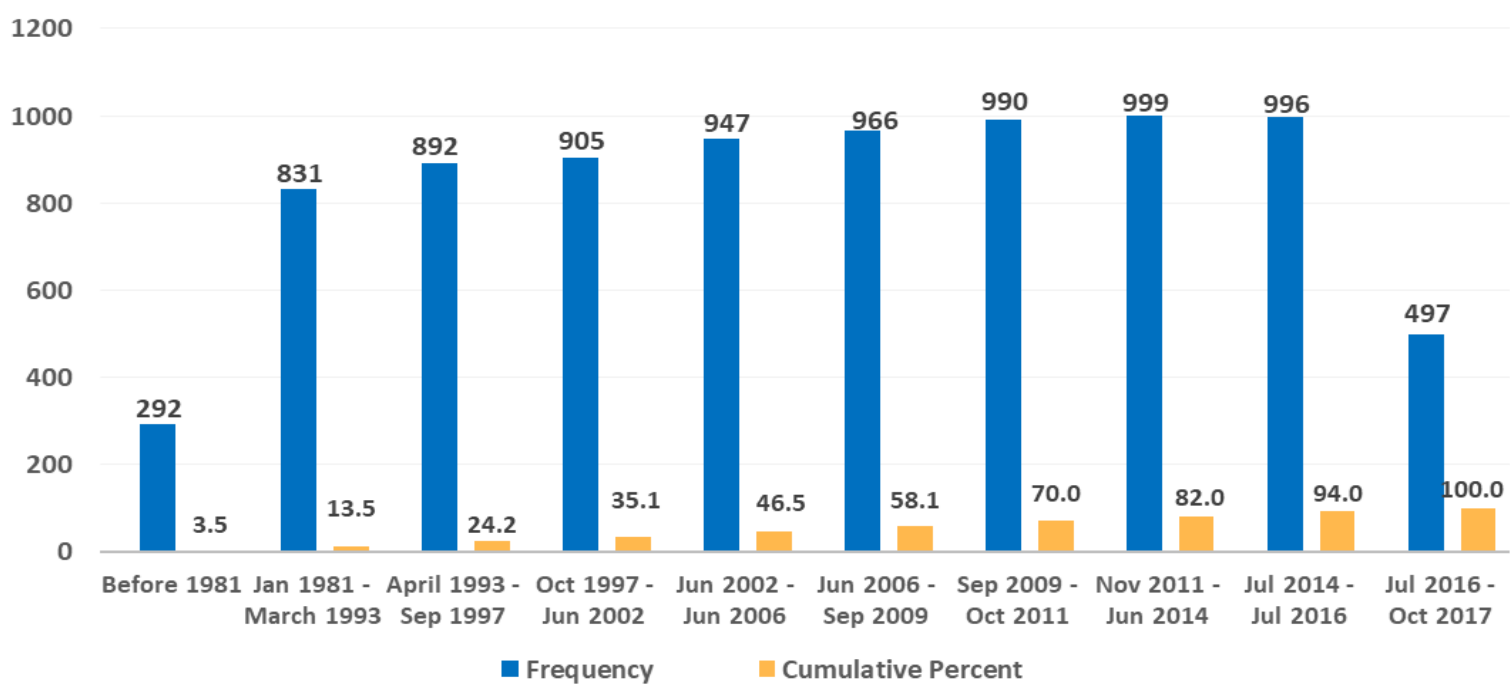

Figure 1. Date of Pharmacists' Registration with the Lebanese Pharmacists Association ( $n=8315$ )

Based on the official list of pharmacists, a random sample of 50 pharmacists who did not start their CE were called and conveyed to a focus group meeting; 30 of them attended the meeting that was held at the OPL premises. It was facilitated by pharmacists of the CE team at the OPL, and the chair of the scientific committee (pharmacist and academic professor). The latter developed the open-ended questions used in the discussion. After a general discussion, participants were divided into 3 groups and the discussion was prompted with each group through questions about the reasons why they did not start their CE yet, and their awareness of the mandatory aspect of the law 190. Facilitators wrote the minutes of the discussion and data transcription and analysis were performed using a written form. Triangulation of the results with those of the survey and their convergence showed that no additional focus groups are necessary.

\section{Ethical Aspects}

The Ethical committee at the Lebanese University waived the need for an ethical approval since this is an observational study that respects participants' confidentiality and autonomy.

\section{RESULTS}

A total of 8315 active members were registered with the OPL till October 2017. This number is steadily increasing as new members apply yearly, typically after graduation (Figure 1).

\section{Learning Management System Data}

Overall Adherence to the CE Program: Among 8315 registered pharmacists, $5679(68.3 \%)$ have started their CE activity, but only 2129 (25.6\%) completed their requirements or more.

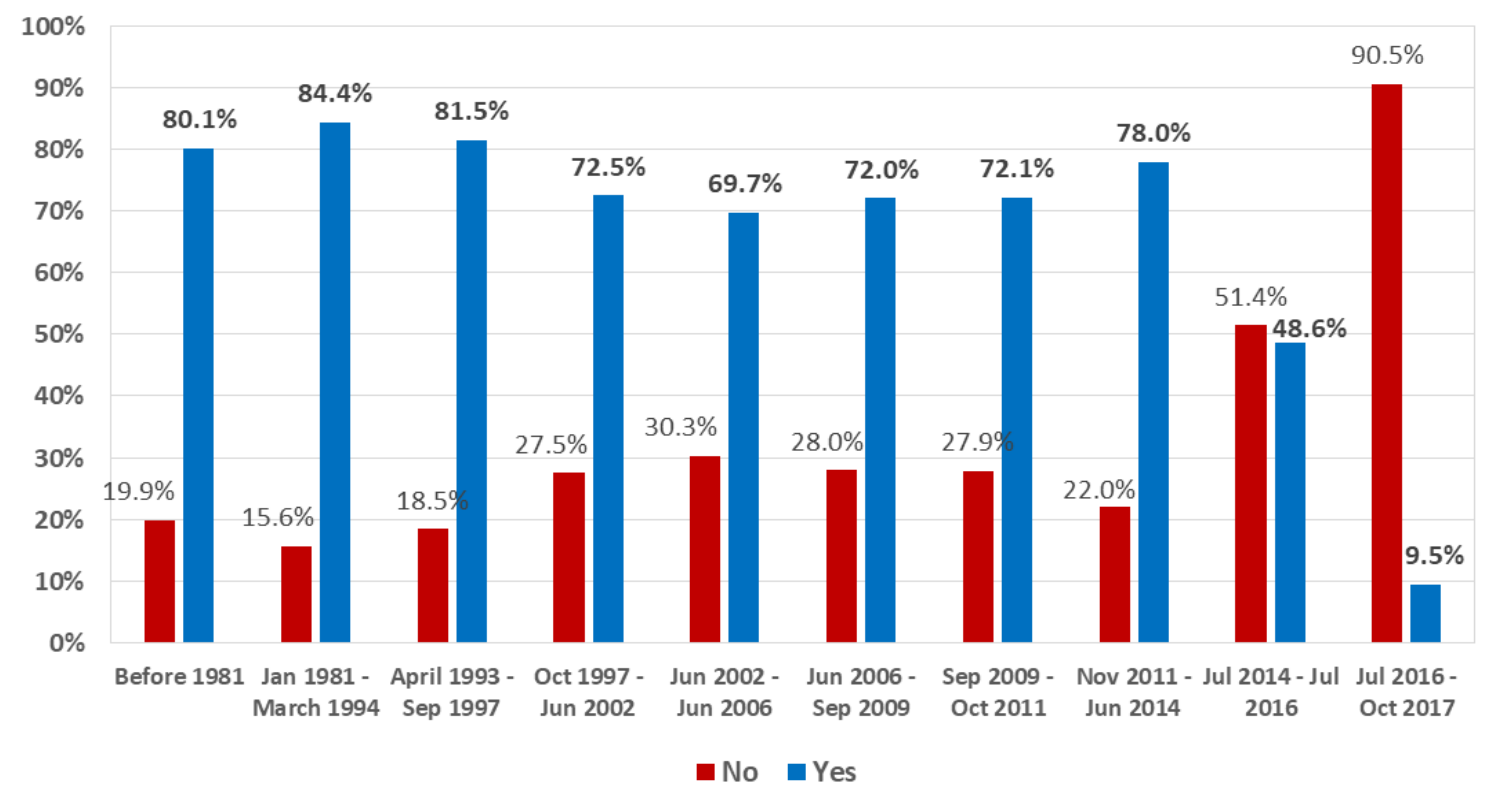

Figure 2. Percentage of 8315 pharmacists who started any continuing education according to registration date with the Lebanese Pharmacists Association 


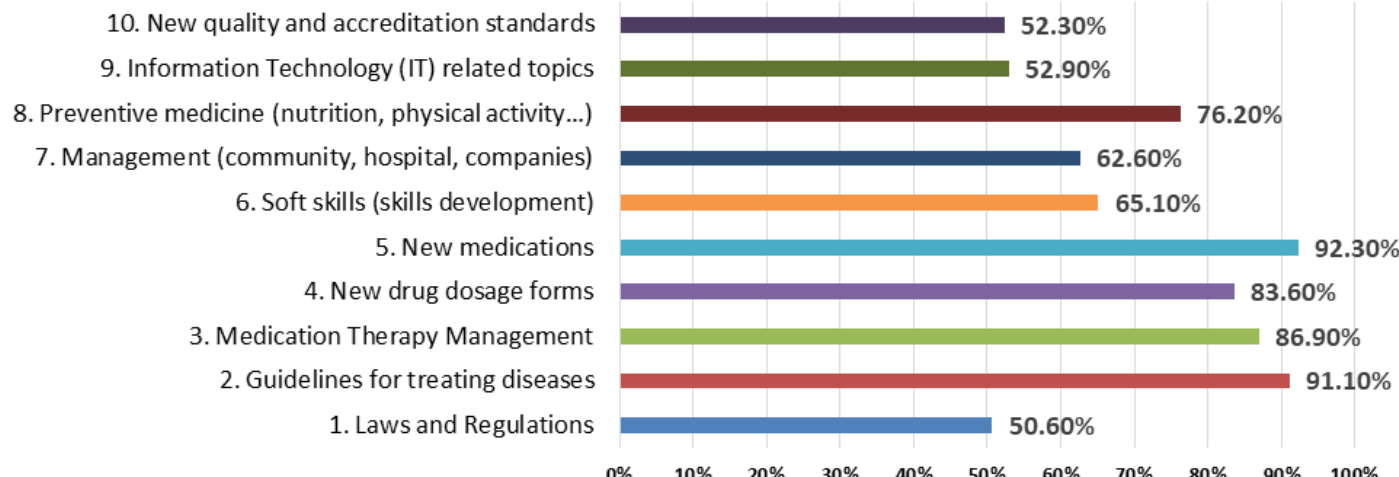

Figure 3. Preferred continuing education topics selected by pharmacists

Percentages of completed credits among registered pharmacists were found to be as follows: $19.9 \%$ completed $25 \%$ of their requirements or less, $22.3 \%$ completed 25.1 $75 \%$ of their requirements, and $8.9 \%$ completed $75.1-100 \%$ of their requirements. Moreover, $17.1 \%$ of registered pharmacists completed more than what is required by the law.

The percentage of pharmacists who have started any type of CE activity after registering with the OPL is shown in Figure 2. Pharmacists registered before October 1997, had the highest percentage of CE activity (above $80 \%$ ) followed by those registered between October 1997 and June 2014 (70-80\%). As for newly registered members, their CE activity is below $50 \%$.

Among pharmacists who started their CE activity, $31.1 \%$ use only live courses. Moreover, $18.7 \%$ completed less than $33 \%$ of their credits using online courses, $25.1 \%$ completed $33-68 \%$ of their credits using online courses, and $25 \%$ completed more than $68 \%$ of their credits using online courses.

\section{Registered Pharmacists' Survey}

Out of the 750 questionnaires distributed, 628 (83.73\%) were filled out and returned to be analyzed. Among the 628 respondents, $567(90.3 \%)$ have earned at least one CE credit. Of those, $5.4 \%$ declared taking mainly online courses, $15.4 \%$ mainly live courses and the remaining both types of CE. Only 12 (1.9\%) declared not being interested in any type of CE.

Among surveyed pharmacists, 204 (32.5\%) selected 1-hour long sessions, $129(20.5 \%)$ sessions of 1 to 2 -hour long, 82 (13.1\%) sessions half a day (4-hour long), 15 (2.4\%) all day long ( 7 hours), 52 (8.3\%) preferred the weekend option (14 hours), 53 (8.4\%) a 3-day option (Annual Congress), and 53 (8.4\%) preferred long-term courses with certification (Masters, University Diploma...). As for the language, 372 (59.2\%) preferred English, 155 (24.7\%) preferred French, while other languages were mentioned (Arabic 44 (7.0\%); Russian 2 (0.3\%); and Spanish $1(0.2 \%))$.

On weekdays, 73 (11.6\%) preferred AM timing, 128 (20.4\%) the PM, 194 (30.9\%) preferred evenings. On weekends, 197 (31.7\%) preferred AM timing, 115 (18.4\%) preferred PM,

\begin{tabular}{|c|c|c|c|c|c|c|}
\hline Question & $\begin{array}{l}\text { Strongly } \\
\text { disagree }\end{array}$ & Disagree & Neutral & Agree & $\begin{array}{c}\text { Strongly } \\
\text { agree }\end{array}$ & $\begin{array}{c}\text { Not } \\
\text { Applicable }\end{array}$ \\
\hline 1. Cost of transportation ( $\mathrm{N}=627 ; 99.84 \%)$ & $124(19.7 \%)$ & $185(29.5 \%)$ & $165(26.3 \%)$ & $54(8.6 \%)$ & $30(4.8 \%)$ & $69(11.0 \%)$ \\
\hline 2. Distance and traffic to venue $(\mathrm{N}=628 ; 100 \%)$ & $26(4.1 \%)$ & $40(6.4 \%)$ & $68(10.8 \%)$ & $246(39.2 \%)$ & $221(35.2 \%)$ & $27(4.3 \%)$ \\
\hline 3. Timing of the talk $(\mathrm{N}=628 ; 100 \%)$ & $12(1.9 \%)$ & $38(6.1 \%)$ & $110(17.5 \%)$ & $254(40.4 \%)$ & 199(31.7\%) & $15(2.4 \%)$ \\
\hline 4. Interest in the topic ( $N=628 ; 100 \%)$ & $34(5.4 \%)$ & $92(14.6 \%)$ & $181(28.8 \%)$ & $238(37.9 \%)$ & $66(10.5 \%)$ & $17(2.7 \%)$ \\
\hline 5. Family commitments ( $\mathrm{N}=627 ; 99.84 \%)$ & $15(2.4 \%)$ & $46(7.3 \%)$ & $125(19.9 \%)$ & $263(41.9 \%)$ & $167(26.6 \%)$ & $11(1.8 \%)$ \\
\hline 6. Work obligations ( $\mathrm{N}=628 ; 100 \%)$ & $6(1.0 \%)$ & $20(3.2 \%)$ & $57(9.1 \%)$ & $250(39.8 \%)$ & $286(45.5 \%)$ & $9(1.4 \%)$ \\
\hline 7. Easier to do online courses $(\mathrm{N}=628 ; 100 \%)$ & $13(2.1 \%)$ & $64(10.2 \%)$ & $137(21.8 \%)$ & $232(36.9 \%)$ & $174(27.7 \%)$ & $8(1.3 \%)$ \\
\hline $\begin{array}{l}\text { 8. Not finding adequate program to meet my practice } \\
\text { needs ( } N=627 ; 99.84 \%)\end{array}$ & $28(4.5 \%)$ & $135(21.5 \%)$ & $240(38.2 \%)$ & $144(22.9 \%)$ & $55(8.8 \%)$ & $25(4.0 \%)$ \\
\hline $\begin{array}{l}\text { 9. Cost to be replaced at the pharmacy/Close the } \\
\text { pharmacy during the CE session (pharmacy owners } \\
\text { only) }(\mathrm{N}=625 ; 99.52 \%)\end{array}$ & $18(2.9 \%)$ & $57(9.1 \%)$ & $152(24.2 \%)$ & $174(27.7 \%)$ & $138(22.0 \%)$ & $86(13.7 \%)$ \\
\hline 10. Language used for the presentation $(\mathrm{N}=628 ; 100 \%)$ & $104(16.6 \%)$ & $187(29.8 \%)$ & $159(25.3 \%)$ & 97(15.4\%) & $33(5.3 \%)$ & $48(7.6 \%)$ \\
\hline 11. I learn very little during live $\mathrm{CE}(\mathrm{N}=628 ; 100 \%)$ & $78(12.4 \%)$ & $200(31.8 \%)$ & $183(29.1 \%)$ & $107(17.0 \%)$ & $28(4.5 \%)$ & $32(5.1 \%)$ \\
\hline $\begin{array}{l}\text { 12. I already attend CE organized by pharmaceutical } \\
\text { companies/international congresses ( } N=627 ; 99.84 \%)\end{array}$ & $24(3.8 \%)$ & $94(15.0 \%)$ & $174(27.7 \%)$ & $205(32.6 \%)$ & $71(11.3 \%)$ & $59(9.4 \%)$ \\
\hline $\begin{array}{l}\text { 13. I am already accessing online CE courses ( } N=627 \text {; } \\
99.84 \%)\end{array}$ & $23(3.7 \%)$ & $110(17.5 \%)$ & $147(23.4 \%)$ & $222(35.4 \%)$ & $90(14.3 \%)$ & $35(5.6 \%)$ \\
\hline $\begin{array}{l}\text { 14. I am exempted (teaching, registered abroad...) } \\
(\mathrm{N}=627 ; 99.84 \%)\end{array}$ & $38(6.1 \%)$ & $137(21.8 \%)$ & $180(28.7 \%)$ & $63(10.0 \%)$ & $17(2.7 \%)$ & $192(30.6 \%)$ \\
\hline $\begin{array}{l}\text { 15. I am not interested in doing any live } \mathrm{CE}(\mathrm{N}=628 \text {; } \\
100 \%)\end{array}$ & $149(23.7 \%)$ & 197(31.4\%) & $129(20.5 \%)$ & $60(9.6 \%)$ & $30(4.8 \%)$ & $63(10.0 \%)$ \\
\hline
\end{tabular}


https://doi.org/10.18549/PharmPract.2019.3.1545

\begin{tabular}{|c|c|c|c|c|c|c|}
\hline Question & $\begin{array}{l}\text { Strongly } \\
\text { disagree }\end{array}$ & Disagree & Neutral & Agree & $\begin{array}{l}\text { Strongly } \\
\text { agree }\end{array}$ & $\begin{array}{c}\text { Not } \\
\text { Applicable }\end{array}$ \\
\hline $\begin{array}{l}\text { 1. Difficulty accessing my OPL e-library account } \\
(\mathrm{N}=628 ; 100 \%)\end{array}$ & $62(9.9 \%)$ & $161(25.6 \%)$ & $118(18.8 \%)$ & $163(26.0 \%)$ & $102(16.2 \%)$ & $22(3.5 \%)$ \\
\hline $\begin{array}{l}\text { 2. Difficulty using the OPL Swank platform }(N=628 \text {; } \\
100 \%)\end{array}$ & $63(10.0 \%)$ & $168(26.8 \%)$ & $131(20.9 \%)$ & $157(25.0 \%)$ & $86(13.7 \%)$ & $23(3.7 \%)$ \\
\hline $\begin{array}{l}\text { 3. Lack of interest in the topics available }(N=628 \text {; } \\
100 \%)\end{array}$ & $53(8.4 \%)$ & $171(27.2 \%)$ & $200(31.8 \%)$ & $140(22.3 \%)$ & $46(7.3 \%)$ & $18(2.9 \%)$ \\
\hline $\begin{array}{l}\text { 4. Not finding adequate program to meet my } \\
\text { practice needs ( } N=628 ; 100 \%)\end{array}$ & $43(6.8 \%)$ & $177(28.2 \%)$ & $193(30.7 \%)$ & $143(22.8 \%)$ & $53(8.4 \%)$ & $19(3.0 \%)$ \\
\hline 5. Family commitments ( $\mathrm{N}=628 ; 100 \%)$ & $39(6.2 \%)$ & $116(18.5 \%)$ & $140(22.3 \%)$ & $219(34.9 \%)$ & $96(15.3 \%)$ & $18(2.9 \%)$ \\
\hline 6. Work obligations ( $\mathrm{N}=628 ; 100 \%)$ & $30(4.8 \%)$ & $83(13.2 \%)$ & $102(16.2 \%)$ & $250(39.8 \%)$ & $147(23.4 \%)$ & $16(2.5 \%)$ \\
\hline $\begin{array}{l}\text { 7. OPL staff not supportive/accessible to help with } \\
\text { e-Library and Swank ( } N=628 ; 100 \%)\end{array}$ & $79(12.6 \%)$ & $193(30.7 \%)$ & $209(33.3 \%)$ & $80(12.7 \%)$ & $42(6.7 \%)$ & $25(4.0 \%)$ \\
\hline 8. Courses only offered in English ( $N=628 ; 100 \%)$ & $101(16.1 \%)$ & $205(32.6 \%)$ & $159(25.3 \%)$ & $101(16.1 \%)$ & $36(5.7 \%)$ & $26(4.1 \%)$ \\
\hline 9. I am already attending live CE $(\mathrm{N}=628 ; 100 \%)$ & $41(6.5 \%)$ & $106(16.9 \%)$ & $189(30.1 \%)$ & $209(33.3 \%)$ & $57(9.1 \%)$ & $26(4.1 \%)$ \\
\hline $\begin{array}{l}\text { 10. I am not interested in doing any online CE } \\
(\mathrm{N}=628 ; 100 \%)\end{array}$ & $132(21.0 \%)$ & $209(33.3 \%)$ & $157(25.0 \%)$ & $61(9.7 \%)$ & $42(6.7 \%)$ & $27(4.3 \%)$ \\
\hline
\end{tabular}

and 57 (9.0\%) preferred evenings.

Preferred topics that pharmacists selected are summarized in Figure 3.

Reasons that prevented pharmacists from attending live CE: The reasons that prevented pharmacists from attending live CE sessions are presented in Table 2.

Reasons that prevented pharmacists from doing online CE: The reasons that prevented pharmacists from doing online CE are presented in Table 3.

\section{Focus group on encountered barriers}

The following issues were raised by pharmacists who have not started their CE yet:

- Resistance to change and lack of motivation: despite the law 190 that made the CE mandatory and conditional for re-licensure to all pharmacists living in Lebanon, many of them still hope that the system would be cancelled: "the new elected board will cancel this law" or "the new board will suspend the application of the CE law". The authors also noted that many pharmacists who are known to be knowledgeable in computer and technology and very active on social media, still did not start their CE because they did not perceive its added value to their daily professional activity: "it is a waste of time because nothing we learn is useful in our daily practice".

- Some pharmacists stated that they were not aware of CE sessions and online system, although a phone-based application was developed and used to communicate with pharmacists about professional issues including CE related information (available since 2009 and downloadable free of charge on Android and iOS phones). In fact, only 3579 pharmacists (43\%) have downloaded this application to date while some of those claim to miss reading incoming messages whether through the application or by SMS (Short Message Service): "although I have the application, I don't read the messages", "I don't read any message from the OPL whether on the app or by SMS", "I don't have the mobile app and I don't want to download it"

- Although scientific sessions were organized by academic and other scientific entities in remote areas to give pharmacists in these regions the opportunity to attend and avoid long commutes, many pharmacists questioned the seriousness of the system and tried to find excuses to escape it; the majority stated lack of time and long distances as major barriers: "even if you are doing in remote areas, it is still not close enough to my work place and it takes me 30 minutes to get to the venue", "I have no one to replace me at the pharmacy even if the conference is presented in a region near my pharmacy".

- Another stated reason was language barrier. In fact, it is recognized that there are no online articles in French or in languages other than English: while in Lebanon the teaching languages of the pharmacy are exclusively French and English, pharmacists educated outside Lebanon ( $10 \%$ of total registered pharmacists) may have different languages i.e. Arabic, Russian, Persian, Italian, etc. and may thus find it hard to attend CE sessions in other languages: "I am a Saint Joseph University graduate and I prefer reading French articles", "English is hard for me to understand, why don't you have Arabic courses online", "why don't you seek Russian online courses".

- Pharmacists from remote Lebanese regions, blamed the lack or bad internet connection and others claimed not to be familiar with new technology for taking online courses: "why don't you come to Hermel region and check the Internet there? It would give you an idea of what we are going through", "I have no Internet nor 3G available in my region. To do online courses I would have to go to a friend or a relative at least 30 kilometers far". Although many introductory sessions to the CE program were organized, and a structured continuous support system was built along with the creation of a clear manual to help the pharmacists' login to their CE accounts, some pharmacists are still finding difficulties in using technology: "I'm not familiar with technology. I prefer live sessions".

\section{DISCUSSION}

Our results showed that among all registered pharmacists, $68 \%$ already started their CE and $25.6 \%$ completed their required credits. The relatively high number of enrollment 
is due to the fact that in 2014, the OPL Council took a decision regarding the internships of pharmacy students in community pharmacies and hospitals: to accept trainees, registered pharmacists had to enroll in the CE program and complete at least 5 credits.

As for CE completion, our results are similar to those of some developing countries such as Namibia, and developed countries where the CE system is not yet "mature" such as Canada where provinces have not the same system or requirements. However, our results are in contrast with those of developed countries such as Australia, the United States, some provinces of Canada, and the UK where participation and completion rates are much higher. ${ }^{2}$ For example, Canadian regions where the CE system is fully functional, such as Alberta, have better results than ours: most pharmacists exceeded the required number of education units and more than 70 percent of the total acquired were obtained by completing correspondence courses, and this more than 30 years ago. ${ }^{19}$ In the UK, 32 to $49.6 \%$ completed the minimal requirements and all surveyed pharmacists agreed on the mandatory aspect of the CE. ${ }^{20}$ In contrast, no information is available about the CE system implementation in neighboring countries, where the system has been adopted so far.

Among pharmacists enrolled in the CE system, the majority $(69 \%)$ used the online courses at least once; this shows that computer literacy is not a barrier to most of these pharmacists. Our results show an opposite preference for online courses compared to Massachusetts pharmacists where $66 \%$ preferred live conferences. ${ }^{21}$ This can be explained by the fact that most Lebanese pharmacists (74.4\%) find commuting to attend live conferences more difficult than just taking online tests in-office or from home due to work or family constraints.

Moreover, age did not seem to be a limiting factor for pharmacists' involvement in the CE system, except for newly registered pharmacists; this might be explained by the fact that pharmacists registered before 2014, attended the training sessions offered at that time in various regions, while the newly graduated pharmacists believe that their scientific knowledge is still fresh and up-to-date. Thus, efforts should be done to motivate younger pharmacists to join the CE system by always offering new hot topics, in addition to live training sessions that would help them access the LMS.

The encountered barriers to starting the CE were family and work obligations, resistance to change, lack of interest, lack of time, difficulties in commuting and technology use. Some of these were similar to those found in developed and developing countries. ${ }^{10,22}$ The top three barriers cited in a recently conducted study in Lebanon were lack of time, work constraints and distance to the venue for live events. ${ }^{22}$ A study conducted in Kenya, showed that the main barriers for not attending local courses or workshops, were the distance to venue $(21.6 \%)$, other commitments (20.9\%) and lack of information on what CE activities are available (19.3\%). ${ }^{10}$ The most cited barriers by Flemish pharmacists were lack of time, uninteresting topics, and family obligations, while the most cited barriers by a sample of US pharmacists were work constraints, distance to venue, family obligations, and uninteresting topics. ${ }^{23,24}$
Lack of time and work obligations were also cited by Egyptian pharmacists. ${ }^{17}$

Furthermore, some Lebanese pharmacists are still not convinced about the usefulness of $\mathrm{CE}$, opposite to the attitude of US pharmacists who perceived mandatory CE as acceptable more than 30 years ago, and to the majority of Irish pharmacists (84\%) who agreed that engaging in CE was essential for all practicing pharmacists. ${ }^{19,25-27}$ Later on, a study conducted in Colorado in 2009 showed that only $10 \%$ of the pharmacists showed lack of interest in the live CE program while in Massachusetts (2012), all the surveyed pharmacists showed motivation for CE. ${ }^{21,26}$ Efforts should be made to increase awareness of the CE system and familiarity with technology, as shown in other countries. ${ }^{6,28}$

The OPL should develop a strategy to motivate and increase the number of enrollments in the CE program by diversifying the topics to serve the interests of all pharmacy sub-specialty areas based on required competencies (particularly selected topics such as clinical topics, preventive medicine, and transferable skills), assessing the overall satisfaction of participants, evaluating the CE program to constantly improve the quality of the sessions presented, offering live sessions in languages other than English or French, offering sessions with various timings to cover all preferences, offering online courses in languages other than English, offering sessions to improve the computer literacy of pharmacists unfamiliar with computer technology, organizing hands-on teaching and workshops instead of theoretical sessions, and developing webinars that can be attended from home or the office to overcome difficulties of attending live conferences. Finally, it is recommended that a survey be conducted to assess the motivation factors among Lebanese pharmacists, and to develop a framework for $\mathrm{CE}$, taking into consideration the recommendations provided by international examples. ${ }^{2,29}$

\section{CONCLUSIONS}

Although results of the present study are similar to those in developing countries, the resistance to change is higher. The Lebanese Pharmacists Association should develop strategies to motivate and enroll more pharmacists in the CE system, based on the barriers and preferences cited in the results, while continuing to offer high quality and costfavorable CE programs to Lebanese pharmacists.

\section{ACKNOWLEDGMENTS}

The Lebanese Pharmacists Association Continuing Education Committee members: Nadia DALLOUL, Rony M. ZEENNY, Sylvia SAADE, and Siham ITANI.

\section{CONFLICT OF INTEREST}

We declare that the first two authors are full-time employees at the Lebanese Pharmacists Association, Drug Information Center Department. Georges Sili is the previous president of the Lebanese Pharmacists Association (non-profit position) and Pascale Salameh is a full-time Professor at the Lebanese University and the previous chair (non-profit position) of the scientific committee at the 
Lebanese Pharmacists Association. We have no other conflict of interest to declare.

\section{FUNDING}

None.

References

1. Rouse MJ. Continuing professional development in pharmacy. Am J Health Syst Pharm. 2004;61(19):2069-2076. https://doi.org/10.1093/ajhp/61.19.2069

2. International Pharmaceutical Federation - FIP. Continuing Professional Development/Continuing Education in Pharmacy: Global Report. The Hague, The Netherlands: International Pharmaceutical Federation. Available at: https://www.fip.org/files/fip/PharmacyEducation/CPD CE report/FIP 2014 Global Report CPD CE online version.pdf (accessed Jul 29, 2019).

3. Rouse MJ, Vlasses PH, Wadelin JW, Zarembski DG, Joshi MP, Mabirizi D, Saleeb SA. Continuing Pharmaceutical Education: Guide to Establishing Quality Assured and Accredited Programs Submitted to the US Agency for Internationa Development by the Systems for Improved Access to Pharmaceuticals and Services (SIAPS) Program. Arlington, VA: Management Sciences for Health. Available at: https://www.acpeaccredit.org/pdf/GuidanceforContinuingPharmaceuticalEducation-SIAPS ACPE-March2016.pdf (accessed Jul 29, 2019). 2016. [Accessed]

4. Council on Credentialing in Pharmacy. Credentialing in pharmacy. The Council on Credentialing in Pharmacy. Am J Health Syst Pharm. 2001;58(1):69-76. https://doi.org/10.1093/ajhp/58.1.69

5. Becher T. The learning professions. Stud Higher Educ. 1996;21(1):43-55. https://doi.org/10.1080/03075079612331381447

6. Biggs D. Issues in continuing professional development for pharmacists. Bulletin of the Kuwait Institute for Medical Specialization. 2003;2:55-58.

7. Daniels AS, Walter DA. Current issues in continuing education for contemporary behavioral health practice. Adm Policy Ment Health. 2002;29(4-5):359-376.

8. Pharmaceutical Society of Australia - PSA. National competency standards framework for pharmacists in Australia. Available from: https://my.psa.org.au/servlet/fileField?entityld=ka17F000000cmnyQAA\&field=PDF File Member Content Body s (accessed Jul 29, 2019).

9. The Joint Commission of Pharmacy Practitioners. An Action plan for Implementation of the JCPP Future Vision of Pharmacy Practice. Available at: https://pcms.ouhsc.edu/ams/common/docs oac/ViewOAC img blobs.asp?DoclD=091276228348 (accessed Jul 29, 2019).

10. Ministry of Medical Services Ministry of Public Health and Sanitation Pharmacy and Poisons Board K. CPD Programs for Pharmacy Professionals Assessment Report on Status of Implementation in Kenya. Available at: http://apps.who.int/medicinedocs/documents/s21952en/s21952en.pdf (accessed Jul 29, 2019).

11. Rayes IK, Hassali MA, Abduelkarem AR. The role of pharmacists in developing countries: The current scenario in the United Arab Emirates. Saudi Pharm J. 2015;23(5):470-474. https://doi.org/10.1016/i.jsps.2014.02.004

12. Kheir N, Fahey M. Pharmacy practice in Qatar: challenges and opportunities. South Med Rev. 2011;4(2):92-96. https://doi.org/10.5655/smr.v4i2.1007

13. Al-Worafi YM. Pharmacy education in Yemen. Am J Pharm Educ. 2013;77(3):65. https://doi.org/10.5688/ajpe77365

14. Fathelrahman A, Ibrahim M, Wertheimer A. Pharmacy practice in developing countries: achievements and challenges: Academic Press; 2016. ISBN: 0128017112

15. Lebanese Pharmacists Association. Law 190 on mandatory continuing education to Lebanese pharmacists. Available from: http://opl.org.lb/newdesign/lawsandregulations.php (accessed Jul 29, 2019).

16. Relias Learning. https://www.relias.com/product/learning-management-system (accessed Jul 29, 2019).

17. Ibrahim OHM. Assessment of Egyptian pharmacists' attitude, behaviors, and preferences related to continuing education Int J Clin Pharm. 2012;34(2):358-363. https://doi.org/10.1007/s11096-012-9616-4

18. Sacre H, Tawil S, Hallit S, Hajj A, Sili G, Salameh P. Continuing Education: Attitudes of Lebanese Pharmacists towards Online and Live Sessions. Pharm Pract (Granada). 2019;17(2):1438. https://doi.org/10.18549/PharmPract.2019.2.1438

19. Friesen AJ, Zinyk DE, Mah G. Mandatory continuing pharmacy education in Alberta, Canada: the response to live programs and correspondence courses. Am J Pharm Educ. 1985;49(2):156-159.

20. Mottram DR, Rowe P, Gangani N, Al-Khamis Y. Pharmacists' engagement in continuing education and attitudes towards continuing professional development. Pharm J. 2002;269(7221):618-622.

21. Young AM. A prescription for reframing continuing pharmacy education in Massachusetts: Northeastern University; 2012.

22. Saade S, Ghazala F, Farhat A, Hallit S. Attitudes towards continuous professional development: a study of pharmacists in Lebanon. Pharm Pract (Granada). 2018;16(1):1103. https://doi.org/10.18549/PharmPract.2018.01.1103

23. Driesen $A$, Leemans $L$, Baert $H$, Laekeman $G$. Flemish community pharmacists' motivation and views related to continuing education. Pharm World Sci. 2005;27(6):447-452. https://doi.org/10.1007/s11096-005-0950-7

24. Hanson AL, Bruskiewitz RH, Demuth JE. Pharmacists' perceptions of facilitators and barriers to lifelong learning. Am $J$ Pharm Educ. 2007;71(4):67. https://doi.org/10.5688/aj710467

25. Osterhaus JT, Gagnon JP. A survey of state board of pharmacy members and continuing education providers' views on continuing education. Drug Intell Clin Pharm. 1985;19(2):134-138. 
26. McConnell KJ, Newlon C, Dickerhofe J. A model for continuing pharmacy education. Am J Pharm Educ. 2009;73(5):87. https://doi.org/10.5688/aj730587

27. Haughey SL, Hughes CM, Adair CG, Bell HM. Introducing a mandatory continuing professional development system: an evaluation of pharmacists' attitudes and experiences in Northern Ireland. Int J Pharm Pract. 2007;15(3):243-249. https://doi.org/10.1211/ijpp.15.3.0012

28. Chiu YL, Liang JC, Mao PC, Tsai CC. Improving Health Care Providers' Capacity for Self-Regulated Learning in Online Continuing Pharmacy Education: The Role of Internet Self-Efficacy. J Contin Educ Health Prof. 2016;36(2):89-95. https://doi.org/10.1097/CEH.0000000000000066

29. Wadelin JW, Travlos DV, Janke KK, Zellmer WA, Vlasses PH. Current and future opportunities and challenges in continuing pharmacy education. Am J Pharm Educ. 2017;81(3):44. https://doi.org/10.5688/ajpe81344 